\title{
PERFIL EPIDEMIOLÓGICO DAS VÍTIMAS DE ACIDENTES DE TRÂNSITO ATENDIDAS NUM SERVIÇO PÚBLICO DE EMERGÊNCIA DA REGIÃO METROPOLITANA DE NATAL/RN
}

\author{
W. M. C. MEDEIROS ${ }^{1}$, C. H. GALVÃ ${ }^{1}$, I. S. C. GUEDES ${ }^{2}$, M. R. CARÍCIO ${ }^{3}$, E. M. F. MACEDO ${ }^{4}$ e L. M. RIBEIRO ${ }^{4}$. \\ ${ }^{1}$ Universidade Federal do Rio Grande do Norte, ${ }^{2}$ Psicóloga Clínica, ${ }^{3}$ Universidade Federal da Paraíba, ${ }^{4}$ Hospital \\ Monsenhor Walfredo Gurgel \\ wilma@ufrnet.br*
}

Submetido 26/07/2016 - Aceito 19/11/2017

DOI: $10.15628 /$ holos.2017.4876

\section{RESUMO}

Devido à frequência de ocorrência e gravidade, os acidentes de trânsito são caracterizados como epidemias para as sociedades atuais e entram na agenda da saúde pública como morbimortalidades por causas externas, acarretando uma série de prejuízos individuais e sociais, como também, elevados custos ao sistema de saúde e ocorrências de sequelas temporárias ou permanentes, até invalidez e óbito. Dada a relevância do tema, este trabalho tem como objetivo descrever o perfil dos pacientes vítimas de acidente de trânsito atendidos no serviço de urgência e emergência do Hospital Monsenhor Walfredo Gurgel, um hospital de referência na cidade de Natal, Brasil. Trata-se de um estudo transversal, incluindo 10.377 pacientes vítimas de acidente de trânsito, atendidos no período de 1 de
\end{abstract}

janeiro a 31 de dezembro de 2014. Os resultados indicam que a maioria das vítimas era do sexo masculino $(76,7 \%)$; as motocicletas são o tipo de veículo mais envolvido em acidentes $(74,2 \%)$ e a faixa etária com maior incidência foi a de 21 a 30 anos (33,93\%). Os principais diagnósticos foram: escoriação e corte $(25,5 \%)$; contusão, entorse e luxação (23\%); fraturas $(21,1 \%)$; trauma crânio-encefálico $(13,9 \%)$ e politraumatismo $(8,8 \%)$. Os resultados estão de acordo com outros estudos da literatura nacional. Como conclusão geral, há a necessidade de aplicação urgente de ações preventivas e de controle voltadas, principalmente, aos jovens do sexo masculino condutores de motocicletas.

PALAVRAS-CHAVE: Acidentes de Trânsito, Ferimentos e Lesões, Serviços de Saúde.

\section{EPIDEMIOLOGICAL PROFILE OF ASSISTED TRAFFIC ACCIDENT VICTIMS IN PUBLIC EMERGENCY THE METROPOLITAN REGION OF NATAL / RN}

\begin{abstract}
Due to the frequency of occurrence and severity, traffic accidents are characterized as epidemics for current societies and enter the public health agenda as morbimortalities due to external causes, leading to a series of individual and social damages, as well as high costs to the health system and occurrences of temporary or permanent sequelae, until disability and death. Given the relevance of the theme, this paper aims to describe the profile of the victims of traffic accidents patients attended at the emergency and emergency service of the Monsenhor Walfredo Gurgel Hospital, it is a reference hospital at Natal city, Brazil. This is a cross-sectional study, including 10,377 traffic
\end{abstract}

accident victim patients attended in the period from January 1 to December 31, 2014. The results indicate that most of the victims were male (76.7\%); motorcycles are the type of vehicle most involved in accidents (74.2\%) and the age group with the highest incidence was 21 to 30 years (33.93\%). The main diagnoses were: excoriation and cut (25.5\%); contusion, sprain and dislocation (23\%); fractures (21.1\%); traumatic brain injury (13.9\%) and polytrauma (8.8\%). The results are in agreement with other studies of the national literature. As a general conclusion, there is a need for urgent application of preventive and control actions, mainly aimed at young male motorcycle drivers.

KEYWORDS: Traffic-Accidents, Wounds and Injuries, Health Services. 


\section{INTRODUÇÃO}

Segundo a Organização Mundial da Saúde (OMS), cerca de 50 milhões de pessoas sofrem lesões e sequelas decorrentes de acidentes de trânsito (AT), levando a 1,3 milhão de óbitos (World Health Organization [WHO], 2010). No Brasil há mais de 150 mil mortos e ou feridos graves anualmente, colocando-o na quinta posição entre os países com maior mortalidade por AT (Falconi Consultores de Resultados, Observatório Nacional de Segurança Viária [ONSV] \& AMBEV S.A, 2014; Waiserlfisz, 2013). Isto caracteriza o fenômeno de AT como uma epidemia em termos de saúde pública, que gera altos custos com internações hospitalares, além de causar diversos transtornos às pessoas envolvidas, como sequelas físicas, econômicas e emocionais, invalidez e até óbitos (Confederação Brasileira dos Municípios [CNM], 2009; Souza \& Lima, 2007; Paixão et al., 2015). Mais especificamente, segundo o Ministério da Saúde (MS), em 2008 ocorreram 39 mil mortes e 619 mil pessoas sofreram lesões, mais ou menos graves, decorrentes de acidentes de trânsito. Tais acidentes representam um custo bastante alto para toda a sociedade, alcançando cerca de 1 a $2 \%$ do Produto Interno Bruto (PIB) dos países, que corresponde a um custo global superior a US\$ 500 bilhões/ano, sendo que somente no Brasil esses custos estão na ordem de R\$ 28 bilhões/ano (Ministério da Saúde [MS], 2013; Instituto de Pesquisa Econômica Aplicada [IPEA], 2006).

Mediante a gravidade desse evento foram geradas algumas iniciativas, como a Política Nacional de Redução da Morbimortalidade por Acidentes e Violências, implantada pelo MS, em 2001 (Ministério da Saúde, 2001); o Projeto de Vigilância de Violências e Acidentes (Viva) para o monitoramento e análise de tendência temporal dos indicadores de morbidade e mortalidade atribuídos aos AT, em 2006 (Mello Jorge, 2013) e nos dias atuais, como estratégia para reduzir as mortes e lesões causadas pelo trânsito, implantou-se o Projeto Vida no Trânsito (PVT), parte do Projeto Road Safety in 10 countries (RS 10), que é uma das ações promissoras para o cumprimento das metas da Década de Ações para a Segurança no Trânsito (2011 a 2020). Atualmente o PVT está implantado em todas as capitais e no Distrito Federal (Morais et al., 2013). Em Natal, o projeto foi implantado em 2013 quando foi instituída a Comissão Municipal Intersetorial de Segurança no Trânsito, pelo Decreto no 10.021, de 19 de julho de 2013 (Prefeitura Municipal de Natal [PMN], 2016).

Mesmo com a implantação das iniciativas e desenvolvimento de ações visando à redução das mortes e das incapacidades das vítimas dos acidentes de trânsito os números ainda são bem representativos, tendo em vista que em 2015, no Brasil, 664,2 mil pessoas se envolveram em AT. Destas, 43 mil foram a óbito e 525 mil ficaram inválidas (Tribuna do Norte, 2016).

Dentre os estados da região Nordeste com maior elevação do risco de morte por acidentes de trânsito estão o Piauí, Paraíba, Sergipe, Maranhão e Rio Grande do Norte (RN), ademais, no RN mais da metade do total de mortes em acidentes de trânsito são representadas por motociclistas (Waiselfisz, 2013).

No RN, de 2001 a 2011, os acidentes de trânsito tiveram aumento da taxa de mortalidade por 100.000 habitantes de 25,6\% (Waiselfisz, 2013). Em 2015, quase 19,5 mil pessoas sofreram AT. Dessas, 16.799 ficaram incapacitadas e 646 foram a óbito. O custo gerado por essa violência foi de 
$\mathrm{R} \$ 2,65$ bilhões, que corresponde a 5,08\% do PIB estadual e ultrapassa a receita total do município de Natal, que é de R\$ 2 bilhões (Tribuna do Norte, 2016).

Em 2014, foram registrados 7.763 acidentes de trânsito, na região metropolitana de Natal, apresentando um aumento de 5,36\% com relação ao ano anterior com 7.368 casos, ocorrendo em média 21 acidentes diários (Secretaria Municipal de Mobilidade Urbana [STTU], 2015).

Todos esses dados apontam a violência no trânsito como uma questão social, que traz transtornos e que exige grande esforço e determinação para ser solucionado, tanto a nível nacional, quanto local, em especial Natal, cidade desse estudo, pois não só constituem quantidade significativa de acidentes, como também, são responsáveis por um relevante número de atendimentos de urgência e emergência em pronto-socorro e de internações hospitalares.

O serviço de urgência e emergência do Pronto Socorro Clóvis Sarinho (PSCS) do Complexo Hospitalar Monsenhor Walfredo Gurgel (HMWG) é referência no atendimento de urgência e emergência no estado do RN, recebendo principalmente as vítimas de trauma, causado em sua grande maioria, por acidentes de trânsito. Atende em média, 13 mil pacientes por mês pelo Sistema Único de Saúde (SUS) e é o único hospital público da região metropolitana de Natal que conta com serviço especializado de queimados, ortopedia, neurologia e neurocirurgia, entre outras especialidades (Governo do Rio Grande do Norte, 2015).

Diante da relevância do problema e da necessidade de se conhecer de forma sucinta o comportamento do agravo frente à população, bem como os tipos de acidentes e suas vítimas, o presente trabalho tem como principal objetivo estudar as características epidemiológicas dos AT e das vítimas atendidas pelo HMWG, no período de 1 de janeiro a 31 de dezembro de 2014. Desta forma, o estudo visa contribuir para o reconhecimento epidemiológico desse agravo, corroborando para o desenvolvimento de estratégias de prevenção e controle, e ações de promoção à saúde, além das práticas assistenciais do serviço de urgência e emergência a essa população.

\section{METODOLOGIA}

Trata-se de um estudo epidemiológico com delineamento transversal, realizado no serviço de urgência e emergência do HMWG, incluindo todos os pacientes, vítimas de acidentes de trânsito, independente do sexo e da idade, que foram atendidos no período de 1 de janeiro a 31 de dezembro de 2014 pelo referido hospital.

Os dados foram coletados do programa Epi Info AT, nos meses de agosto e setembro de 2015, sendo selecionadas as vítimas de acidentes de transporte (Código Internacional de Doenças - CID 10 - V01 a V89) (Departamento de Informática do SUS [DATASUS], 2016), que se constituem em acidentes de trânsito (evento ocorrido na via pública). Embora possam existir algumas diferenças nas definições de acidentes de trânsito e transporte, optou-se pela terminologia acidente de "trânsito", por esta ser a mais conhecida.

Quando da realização da coleta, o aplicativo Epi Info AT gerou arquivos contendo os dados de acidentes de trânsito em separado, mês a mês, no formato xls (eXcel Spreadsheet) que puderam ser executados através do software Microsoft Office Excel. 
Os dados coletados (mês a mês - janeiro, fevereiro etc.) foram organizados, então, com o auxílio do Microsoft Office Excel 2010, em tabelas (mês a mês) e em seguida, consolidadas em uma única tabela, que apresentou os dados de AT anualmente e não separado por mês. Com os dados organizados em tabelas, por ano, foi aplicada a estatística descritiva, sendo estimada a frequência simples e relativa para as variáveis do estudo, em relação às vítimas: sexo, idade (agrupadas em faixas etárias), raça e estado civil; ao meio de transporte que sofreu ou provocou o acidente e a natureza da lesão, bem como a evolução do caso e a escolaridade.

Para organização e análise descritiva dos dados inerentes ao estudo, foi utilizado o Microsoft Office Excel 2010.

A pesquisa foi realizada com dados secundários, não sendo necessário submetê-la ao Comitê de Ética em Pesquisa da UFRN.

\section{RESULTADOS}

Em 2014, o PSCS do HMWG atendeu 10.377 vítimas de acidentes de trânsito. Conforme a Tabela 1, que apresenta as variáveis demográficas, observa-se que houve maior número de vítimas de acidente de trânsito com relação ao sexo masculino $(76,7 \%)$. Quanto à faixa etária das vítimas, pode-se observar que a faixa mais representativa foi de 21 a 30 anos (33,9\%), seguida de 31 a 40 anos e 11 a 20 anos. Essas duas faixas etárias concentram a grande maioria dos casos $(73,4 \%)$, de acordo com o explicitado no gráfico da Figura 1 . Quanto à cor/raça, houve uma grande representatividade na cor parda (93,8\%). Quanto ao estado civil, os solteiros evidenciaram a maioria, com (63,9\%). Na escolaridade, a informação ficou comprometida, já que na maioria dos casos esse dado não foi registrado $(68,2 \%)$, porém dentre os declarantes a maioria tinha o ensino fundamental incompleto $(15,3 \%)$.

Tabela 1: Perfil demográfico das vítimas de acidentes de trânsito, atendidas no PSCS do HMWG, no período de janeiro a dezembro de 2014 - Natal/RN.

\begin{tabular}{l|c|c}
\hline Variáveis & $\mathbf{n}$ & $\mathbf{\%}$ \\
\hline Sexo & & \\
Masculino & 7.962 & $\mathbf{7 6 , 7 \%}$ \\
Feminino & 2.415 & $23,3 \%$ \\
Idade & & \\
0 a 10 & 530 & $5,1 \%$ \\
11 a 20 & 1.971 & $18,9 \%$ \\
$\mathbf{2 1}$ a 30 & 3.521 & $\mathbf{3 3 , 9 \%}$ \\
$\mathbf{3 1}$ a 40 & $\mathbf{2 . 1 3 5}$ & $\mathbf{2 0 , 6 \%}$ \\
41 a 50 & 1.188 & $11,5 \%$ \\
51 a 60 & 627 & $6,0 \%$ \\
61 a 70 & 222 & $2,1 \%$ \\
71 a 80 & 109 & $1,1 \%$ \\
81 e mais & 43 & $0,4 \%$ \\
Cor/Raça & & \\
Amarela & 64 & $0,6 \%$ \\
Branca & 377 & $3,6 \%$ \\
Indígena & 12 & $0,1 \%$ \\
Parda & 9.732 & $\mathbf{9 3 , 8 \%}$
\end{tabular}


Preta

Estado civil

Casado

Solteiro

Escolaridade

Ensino fundamental completo

Ensino fundamental incompleto

Ensino médio completo

Ensino médio incompleto

Ensino superior completo

Ensino superior incompleto

Analfabetos

Não se aplica

Ignorado

\begin{tabular}{c|c}
128 & $1,2 \%$ \\
2.212 & $21,3 \%$ \\
6.633 & $63,9 \%$ \\
& \\
152 & $1,5 \%$ \\
1.592 & $15,3 \%$ \\
706 & $6,8 \%$ \\
436 & $4,2 \%$ \\
76 & $0,7 \%$ \\
84 & $0,8 \%$ \\
99 & $1 \%$ \\
159 & $1,5 \%$ \\
7.073 & $68,2 \%$ \\
\hline
\end{tabular}

Fonte: Base de dados Epi Info AT/HMWG.

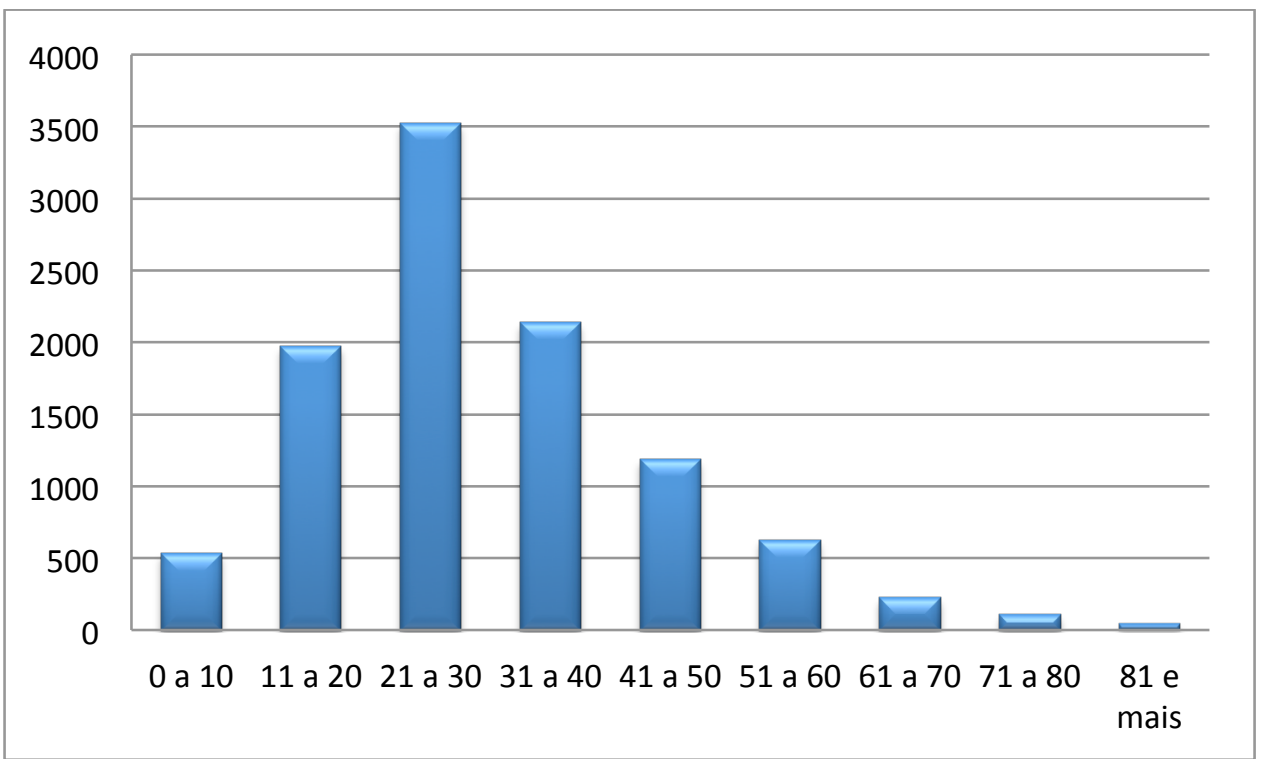

Figura 1: Vítimas de acidentes de trânsito por faixa etária.

Fonte: Base de dados Epi Info AT/HMWG.

Com relação ao tipo de veículo envolvido no acidente de trânsito, conforme a Tabela 2 foi observado que a grande maioria dos casos envolveu motocicleta, que correspondeu a 7.700 (74,2\%) dos acidentados. Em seguida, os pedestres com 912 (8,8\%) ocorrências; automóvel com 883 (8,5\%); bicicleta com 639 (6,2\%); coletivo com 64 (0,6\%), animais com 63 (0,6\%) e carroça com $42(0,4 \%)$; sendo $74(0,7 \%)$ de casos ignorados.

Tabela 2: Caracterização do veículo utilizado pelas vítimas de acidentes de trânsito, atendidas no PSCS do HMWG, no período de janeiro a dezembro de 2014 - Natal/RN.

\begin{tabular}{l|c|c}
\hline Variável & $\mathbf{n}$ & $\mathbf{\%}$ \\
\hline Automóvel & 883 & $8,5 \%$ \\
Motocicleta & $\mathbf{7 . 7 0 0}$ & $\mathbf{7 4 , 2 \%}$ \\
Bicicleta & 639 & $6,2 \%$
\end{tabular}




\begin{tabular}{l|c|c} 
Pedestre & 912 & $8,8 \%$ \\
Coletivo & 64 & $0,6 \%$ \\
Animal & 63 & $0,6 \%$ \\
Carroça & 42 & $0,4 \%$ \\
Ignorado & 74 & $0,7 \%$ \\
\hline
\end{tabular}

Fonte: Base de dados Epi Info AT/HMWG.

Quanto à distribuição dos traumas, a Tabela 3 apresenta os seguintes tipos de lesões: 2.649 (25,5\%) escoriação e corte; 2.388 (23,0\%) contusão, entorse e luxação; 2.193 (21,1\%) fratura; $1.445(13,9 \%)$ trauma crânio encefálico; $917(8,8 \%)$ politraumatismo; 249 (2,4\%) traumatismo dentário; 85 (0,8\%) lesão dos órgãos internos do tórax; $65(0,6 \%)$ abdômen; 32 (0,3\%) queimadura; 30 (0,29\%) amputação e 19 (0,2\%) perfuração e laceração 19 (0,2\%).

Tabela 3: Caracterização do tipo de lesões das vítimas de acidentes de trânsito, atendidas no PSCS do HMWG, no período de janeiro a dezembro de 2014 - Natal/RN.

\begin{tabular}{l|c|c}
\hline Variável & $\mathbf{n}$ & $\mathbf{\%}$ \\
\hline Escoriação e Corte & $\mathbf{2 . 6 4 9}$ & $\mathbf{2 5 , 5 \%}$ \\
Contusão, entorse e luxação & 2.388 & $23,0 \%$ \\
Fratura & 2.193 & $21,1 \%$ \\
Trauma crânio encefálico & 1.445 & $13,9 \%$ \\
Politraumatismo & 917 & $8,8 \%$ \\
Traumatismo dentário & 249 & $2,4 \%$ \\
Lesão dos órgãos internos do tórax & 85 & $0,8 \%$ \\
Abdômen & 65 & $0,6 \%$ \\
Queimadura & 32 & $0,3 \%$ \\
Amputação & 30 & $0,3 \%$ \\
Perfuração e laceração & 19 & $0,2 \%$ \\
\hline
\end{tabular}

Fonte: Base de dados Epi Info AT/HMWG.

Quanto à característica da evolução hospitalar dos pacientes, pode-se observar a partir dos dados descritos na Tabela 4 que a maioria dos casos foi de atendimento ambulatorial com 7.705 $(74,2 \%)$ casos; seguido de 1.482 (14,3\%) internações que receberam alta; 26 (0,3\%) casos de óbitos; 39 (0,4\%) evasão ou fuga e 1.125 (10,8\%) com dados ignorados.

Tabela 4: Caracterização da evolução clínica hospitalar das vítimas de acidentes de trânsito, atendidas no PSCS do HMWG, no período de janeiro a dezembro de 2014 - Natal/RN.

\begin{tabular}{l|c|c}
\hline Variável & $\mathbf{n}$ & $\mathbf{\%}$ \\
\hline Atendimento ambulatorial & $\mathbf{7 . 7 0 5}$ & $\mathbf{7 4 , 2} \%$ \\
Internados que receberam alta & 1.482 & $14,3 \%$ \\
Óbitos & 26 & $0,3 \%$ \\
Evasão ou fuga & 39 & $0,4 \%$ \\
Dados ignorados & 1.125 & $10,8 \%$ \\
\hline
\end{tabular}

Fonte: Base de dados Epi Info AT/HMWG.

\section{DISCUSSÃO}

Como consequência direta do aumento expressivo do número de veículos circulantes e da alta frequência de comportamentos de risco, aliados a uma fiscalização insuficiente, os acidentes 
de trânsito envolvendo veículos a motor passaram a se constituir como causa importante de traumatismos na população brasileira (Minayo, 2007). Devido à relevância do problema, tornou-se de grande importância a realização de estudos que objetivem caracterizar o perfil epidemiológico de vítimas de acidentes de trânsito de modo a nortear políticas públicas e estratégias de vigilâncias em saúde mais eficazes (WHO, 2011). Nesse sentido, no presente estudo procurou-se caracterizar o perfil epidemiológico dos pacientes atendidos no PSCS do HMWG vítimas de acidentes de trânsito.

Quanto às variáveis demográficas, observou-se neste estudo que a maioria dos acidentados é do sexo masculino (76,7\%), na faixa etária de 21 a 30 anos (33,9\%), cor parda $(93,8 \%)$ e solteiro $(63,9 \%)$. Quanto à escolaridade, embora tenha sido identificado um significativo número de dados ignorados $(68,2 \%)$, ainda se apresenta representativo o percentual de vítimas com ensino fundamental incompleto (15,3\%). Estes resultados estão em consonância com outros estudos encontrados na literatura, que enfatizam a predominância de homens jovens adultos acidentados (Bastos, Andrade, \& Soares, 2005; Caixeta, Minamisava, \& Oliveira, 2010; Costa \& Mangueira, 2014; Gawryszewski et al., 2009; Reichenheim et al., 2011). Assim, pode-se inferir através desses estudos epidemiológicos que acidente de trânsito tem característica de distribuição diferenciada para sexo, idade, grupos sociais e escolaridade, o que revela situações específicas de vulnerabilidade.

Teorias sobre o comportamento têm algumas hipóteses explicativas para o fato de os adolescentes e adultos jovens serem mais acometidos por acidentes e violências. Inexperiência, busca de emoções, prazer em experimentar sensações de risco, impulsividade e abuso de álcool ou drogas são termos associados aos comportamentos de adolescentes e adultos jovens que podem contribuir para a maior incidência de acidentes de trânsito nessas faixas etárias (Bastos, Andrade, \& Soares, 2005; Paixão et al., 2015).

A predominância do sexo masculino nos acidentes de trânsito apresenta como consequência uma maior taxa de mortalidade entre indivíduos homens, como apontado por uma revisão realizada sobre os acidentes no Brasil no período de 1998-2010 (Bacchieri \& Barros, 2011). Essa predominância mostra os comportamentos determinados socialmente e culturalmente, fazendo assumir maiores riscos nas conduções dos veículos, com maior velocidade, manobras arriscadas, uso de bebida alcoólica, formas de manusear o meio de locomoção, entre outros (Almeida, 2013; Mello Jorge, 2013).

Quanto à característica do meio de locomoção utilizado pela vítima no momento do acidente, neste estudo constatou-se que a grande maioria das vítimas utilizava motocicleta (74,2\%), o que corrobora com outros estudos da literatura (Bacchieri \& Barros, 2011; Bastos, Andrade, \& Soares, 2005; Costa \& Mangueira, 2014; Farias, Barros, \& Rocha, 2009; Morais Neto et al., 2012; Rocha \& Schor, 2013).

É inegável que houve um aumento significativo da frota de motocicletas nas últimas décadas no país, que passou a ser um meio de transporte ágil, econômico e de custo mais acessível à população de baixa renda (Waiselfisz, 2013). Este aumento de frota explica em parte a ocorrência dos acidentes por motocicletas. Porém, além disso, há outros fatores influenciadores, 
como: perfil do motociclista, que é jovem, do sexo masculino, com baixa escolaridade, que se caracteriza com um grupo com característica mais imprudente no trânsito; falta de educação no trânsito, tanto de motociclistas quanto de condutores de outros tipos de veículos; vias inadequadas para o convívio adequado entre motocicletas e outros veículos e legislação mais rígida para condução de motocicleta. Para corroborar com este último aspecto, pode-se citar o veto ao artigo 56 do Código de Trânsito Brasileiro (CTB), que proibia ao motociclista a passagem entre veículo de filas adjacentes, em nome da "maior agilidade de deslocamento" em detrimento da segurança dos usuários de vias públicas (Bacchieri \& Barros, 2011).

Além disso, no contexto brasileiro não se pode negligenciar o fato de que a motocicleta vem se consolidando não somente como um meio de transporte para trabalho e lazer, mas essencialmente como um instrumento de trabalho por parte da população com baixa renda (Bacchieri \& Barros, 2011), como são os casos de motoboy (serviços de entrega) e mototáxi (serviço de transporte de passageiro), que se caracterizam como grupo vulnerável (Amorim, E. Araújo, Araújo, \& Oliveira, 2012; Veronese \& Oliveira, 2006). Sendo evidente o relevante papel social desempenhado pela motocicleta no trabalho e no lazer, quer por deslocamento de pessoas ou pelos serviços prestados, mesmo diante dessa situação, a composição da frota se apresenta como irreversível.

Quanto à caracterização do tipo de lesões de vítimas de acidente de trânsito, neste estudo observou-se que os achados como escoriações e cortes $(25,5 \%)$, seguidas de contusões, entorses e luxações $(23,0 \%)$ e fraturas $(21,1 \%)$ foram relevantes. Porém, trauma crânio encefálico $(13,9 \%)$ e politraumatismo $(8,8 \%)$ se caracterizaram como os mais severos. Novamente, percebe-se com os resultados obtidos estão em conformidade com a literatura (Cabral, Souza, \& Lima, 2011; Debieux, Chertman, Mansur, Dobashi, \& Fernandes, 2010; Parreira, Gregorut, Perlingeiro, Solda, \& ASSEF, 2012). Como o tipo de lesão está fortemente relacionada ao tipo de veículo envolvido no acidente, observou-se que de acordo com as lesões identificadas neste estudo, às mesmas estão associadas com acidentes envolvendo motocicletas e em conformidade com outros estudos específicos sobre acidentes com motociclistas encontrados na literatura (Sado, Morais, \& Viana, 2009; Santos, Moura, Nunes, Leal, \& Teles, 2008; Soares, Mathias, Silva, \& Andrade, 2011, Veronese, Oliveira, \& Shimitz, 2006). Um outro aspecto importante que pode ser analisado, que está fora do escopo deste trabalho, é o relacionamento do agravo da lesão em função do uso ou não de equipamento de segurança (Malta et al., 2006).

Com relação aos aspectos de atendimento das vítimas de acidente de trânsito, pode-se perceber que os custos da violência no trânsito têm forte impacto financeiro sobre o sistema público de saúde (Rodrigues, Cerqueira, Lobão, \& Carvalho, 2009). No caso do HMWG, observouse em 2014 houve mais de 7 mil atendimentos ambulatoriais e mais de mil e quinhentas internações hospitalares, que possivelmente geraram custos bastante representativos ao sistema Único de Saúde (SUS).

\section{CONCLUSÃO}

Neste estudo foi possível caracterizar o perfil das vítimas de acidentes de trânsito atendidas no PSCS do HMWG, tornando evidente que a maioria das vítimas de acidentes de 
trânsito em Natal-RN são adultos jovens, em idade produtiva, solteiros, do sexo masculino e condutores de motocicleta. Como este perfil corresponde a um indivíduo produtivo, acarreta, além dos impactos sociais e emocionais (CAVALCANTE et al., 2009), um forte efeito econômico, uma vez que esses jovens estão em plena faixa economicamente ativa da população.

Ademais, pode-se afirmar que esse perfil se constitui um grupo vulnerável, que está propenso e sujeito a adquirir lesões e traumas, que podem provocar a morte ou limitações, temporárias ou definitivas, de suas atividades diárias, com sério comprometimento no retorno ao trabalho e à sua produtividade. Diante desta constatação é urgente a tomada de ações governamentais direcionadas, quer por regulações, vigilância ou por campanhas educacionais. Da mesma forma, os resultados ora apresentados poderão nortear as práticas assistenciais do serviço de urgência e emergência a essa população. Como é o caso do Projeto Vida no Trânsito, que visa redução de mortes e lesões no trânsito a partir da qualificação da informação e das ações intersetoriais.

\section{REFERÊNCIAS}

Amorim, C.R.; Araújo, E.M.; Araújo, T.M.; Oliveira, N.F. (2012). Acidentes de trabalho com mototaxistas. Rev Bras Epidemiol. v.15, n.1, p.25-27.

Bacchieri, G; Barros, A.J.D. (2011). Acidentes de trânsito no Brasil de 1998-2010: muitas mudanças e poucos resultados. Rev. Saúde Pública; v.45, p.949-63.

Bastos, Y.G.L.; Andrade, S.M.; Soares, D.A. (2005). Características dos acidentes de trânsito e das vítimas atendidas em serviço pré-hospitalar em cidade do Sul do Brasil, 1997/2000. Cad. Saúde Pública. v.21, p.815-22.

Cabral, A.P.S., Souza, W.V.; Lima, M.L.C. (2011). Serviço de Atendimento Móvel de Urgência: um observatório dos acidentes de transportes terrestre em nível local. Rev Bras Epidemiol, v.14, n.1, p.3-14.

Caixeta, C.R.; Minamisava, R.; Oliveira, L.M.A.C.; Brasil, V.V. (2010). Morbidade por acidentes de transporte entre jovens de Goiânia, Goiás. Ciência \& Saúde Coletiva, v.15, n.4, p.2075-2084.

Cavalcante, F.G.; Morita, P.A.; Haddad, S.R. (2009). Sequelas invisíveis dos acidentes de trânsito: o transtorno de estresse pós-traumático como problema de saúde pública. Cien Saúde Colet. v.14, n.5, p.1763-72.

Confederação Brasileira dos Municípios - CNM. (2009). Mapeamento das mortes por acidentes de trânsito no Brasil. Estudos Técnicos da Confederação Brasileira dos Municípios, Brasília.

Costa, M.J.C; Mangueira, J.O. (2014). Perfil epidemiológico de ocorrência no trânsito no Brasil Revisão integrativa. SANRE, Sobral, v.13, n.2, p.110-116.

Debieux, P.; Chertman, C.; Mansur, N.S.; Dobashi, E.; Fernandes, H.J. (2010). Lesões do aparelho locomotor nos acidentes com motocicleta. Acta Ortop Bras. v.18, n.6, p.353-6. 
Departamento de Informática do SUS - DATASUS, 2016.

http://www.datasus.gov.br/cid10/V2008/WebHelp/v01_v99.htm.

Falconi Consultores de Resultados, Observatório Nacional de Segurança Viária (ONSV) e AMBEV S.A. (2014). Retrato da Segurança Viária no Brasil. São Paulo.

Farias, G.M.; Barros, W.C.T.S; Rocha, K.M.M. (2009). Caracterização dos Condutores de Motocicleta Vítimas de Acidentes de Trânsito Atendidos em Hospital de Urgência. Revista de Enfermagem da UFPE on line. v.3, n.4, p.898-907.

Gawryszewski, V.P.; Coelho, H.M.M.; Scarpelini, S.; ZAN, R.; Mello Jorge, M.H.P.; Rodrigues, S.E.M. (2009). Perfil dos atendimentos a acidentes de transporte terrestre por serviços de emergência em São Paulo. Rev Saúde Pública. v.43, n.2, p.275-82.

Governo do Rio Grande do Norte. (2016). Disponível em: http://www.walfredogurgel.rn.gov.br/Conteudo.asp?TRAN=ITEM\&TARG=33384\&ACT=\&PAGE $=0 \& P A R M=\& L B L=$ Institui\%E7\%E3o\#sthash.PI2LPmxN.dpuf.

Instituto de Pesquisa Econômica Aplicada - IPEA. (2006). Impactos sociais e econômicos dos acidentes de trânsito nas rodovias brasileiras. Brasília: IPEA/DENATRAN/ANTP.

Malta, D.C.; Andrade, S.S.C.A.; Gomes, N.; Silva, M.M.A.; Moraes Neto, O.L.; Reis, A.A.C.; Nardi, A.C.F. (2016). Lesões no trânsito e uso de equipamento de proteção na população brasileira, segundo estudo de base populacional. Ciência e Saúde Coletiva, v.21, n.2, p.399-409.

Mello Jorge, M.H.P. (2013). Acidentes de trânsito no Brasil: um atlas de sua distribuição. São Paulo: ABRAMET,

Minayo, M.C.S. (2007). Trajetória histórica de inclusão da violência na agenda do setor saúde. In: Minayo MCS, Deslandes SF, organizadoras. Análise diagnóstica da política nacional de saúde para redução de acidentes e violências. Rio de Janeiro: Fiocruz; p.17-29.

Ministério da Saúde. (2001). Política nacional de redução da morbimortalidade por acidentes e violências. Brasília: Ministério da Saúde.

Ministério da Saúde. Brasília. (2013). Acessado em junho de 2016. Disponível em: http://www.isaudebahia.com.br/noticias/detalhe/noticia/ministerio-da-saude-investe-noatendimento-as-vitimas-de-trauma/.

Morais Neto, O.L.; Montenegro, M.M.S.; Monteiro, R.A.; Siqueira Júnior, J.B.; Silva, M.M.A.; Lima, C.M. et al. (2012). Mortalidade por acidentes de transporte terrestre no Brasil na última década: tendência e aglomerados de risco. Cien Saude Colet. v.17, n.9, p.2223-36.

Morais O. L. N.; Silva M. M. A.; Lima, C. M.; Malta, D. C.; Silva, J. R. J. B. et al. (2015). Vida no Trânsito Project: evaluation of the implementation in five Brazilian state capitals, 2011-2012. Epidemiol. Serv. Saúde. sep. 2013, vol.22, no.3, p.373-382. Disponível em: http://scielo.iec.pa.gov.br/pdf/ess/v22n3/v22n3a02.pdf. 
Paixão, L.M.M.; Gontijo, E.D.; Mingot, S.A.; Costa, D.A.S.; Friche, A.A.L.; Caiaffa, W.T. (2015). Óbitos no trânsito urbano: qualificação da informação e caracterização de grupos vulneráveis. Cad. Saúde Pública, v.31, Sup1, S1:S15.

Parreira, J.G.; Gregorut, F.; Perlingeiro, J.A.G.; Solda, S.C.; Assef, J.C. (2012). Análise comparativa entre as lesões encontradas em motociclistas envolvidos em acidentes de trânsito e vítimas de outros mecanismos de trauma fechado. Rev Assoc Med Bras, v.58, n.1, p.76-81.

Prefeitura Municipal de Natal - PMN. (2016). http://www.natal.rn.gov.br/noticia/ntc-18251.html.

Reichenheim, M.E.; Souza, E.R.; Moraes, C.L.; Mello Jorge, M.H.P.; Silva, C.M.F.P. Minayo, M.C.S. (2011). Violência e lesões no Brasil: efeitos, avanços alcançados e desafios futuros. The Lancet, v.6736, n.11, p.75-89.

ROCHA, G.S.; SCHOR, N. Acidentes de motocicleta no município de Rio Branco: caracterização e tendências. Cien Saude Colet., v.18, n.3, p.721-31, 2013.

Rodrigues, R.I.; Cerqueira, D.R.C.; Lobão, W.J.A.; Carvalho, A.X.Y. (2009). Os custos da violência para o sistema público de saúde no Brasil: informações disponíveis e possibilidades de estimação. Cad. Saúde Pública, v.25, n.1, p.29-36.

Sado, M.J.; Morais, F.D.; Viana, F.P. (2009). Caracterização das vítimas por acidentes motociclísticos internadas no hospital de urgências de Goiânia. Revista Movimenta, v.2, n.2, p.49-53.

Santos, A.M.; Moura, M.E.; Nunes, B.M.; Leal, C.F.; Teles, J.B. (2008). Perfil das vítimas de trauma por acidente de moto atendidas em um serviço público de emergência. Caderno de Saúde Pública. V.24, n.8, p.1927-1938.

Soares, D.F.P.P.; Mathias, T.A.F.; Silva, D.W. (2011). Andrade, S.M. Motociclistas de entrega: algumas características dos acidentes de trânsito na região sul do Brasil. Rev Bras Epidemiol. v.14, n.3, p.433-444.

Souza, E.R.; Lima, M.L.C. Panorama da violência urbana no Brasil e suas capitais. (2007). Ciência e Saúde Coletiva, v.11, p.211-1222.

Secretaria Municipal de Mobilidade Urbana - STTU. (2015). Anuário estatístico 2014: Acidentes de trânsito do município de Natal. Disponível em: http://www.mapadaviolencia.org.br/pdf2013/mapa2013_transito.pdf. Acesso em: 30/09/2015.

Tribuna do Norte. (2016). http://www.tribunadonorte.com.br/noticia/custo-de-acidentes-superar-2-6-bi/350747.

Veronese, A.M.; Oliveira, D.L.L.C.; Shimitz, T.S.D. (2006). Caracterização de motociclistas internados no Hospital de Pronto-Socorro de Porto Alegre. Revista Gaúcha de Enfermagem, Porto Alegre (RS), v.27, n.3, p.379-85.

Veronese, A.M.; Oliveira, D.L.L.C. (2006). Os riscos dos acidentes de trânsito na perspectiva dos moto-boys: subsídios para promoção da saúde. Cad. Saúde Pública, v.22, n.12, p.2717-2721. 
Waiselfisz, J.J. (2013). Mapa da violência - Acidentes de trânsito em motocicletas, Brasília, Unesco, Instituto Airton Senna.

World Health Organization - WHO. (2010). The UN tackles road safety. Geneva. Acessado em junho de 2016. Disponível em: http://www.who.int/mediacentre/news/notes/2010/traffic_injuries_media_20100303/en/. 